\title{
Parity and bladder cancer risk: a dose-response meta-analysis
}

\author{
Yunjin $\mathrm{Bai}^{\dagger}$, Xiaoming Wang ${ }^{\dagger}$, Yubo Yang, Yin Tang, Jia Wang and Ping Han ${ }^{*}$
}

\begin{abstract}
Background: Multiple studies have reported evidence of an inverse association between parity and bladder cancer risk. However, a comprehensive and quantitative assessment of this association has never been conducted. We conducted this study to clarify this issue.

Methods: Systematic search of PubMed and Embase was performed to identify all the studies. Studies were selected based on strict screening with inclusion and exclusion criteria. Summary relative risks (RR) with 95\% confidence intervals $(\mathrm{Cl})$ were calculated by using a fixed-effect model, and the generalized least squares trend estimation was employed to compute study-specific RR and 95\% Cl per live birth increase. Heterogeneity and publication bias were also evaluated.
\end{abstract}

Results: Twelve studies (6,214 cases and 2,693,350 non-cases) were eligible in this meta-analysis. The pooled RR of bladder cancer for parous versus nulliparous women was 0.76 ( $95 \% \mathrm{Cl}: 0.70-0.82$ ). Results were similar in the studies that adjusted for $\mathrm{BMI}(\mathrm{RR}=0.66 ; 95 \% \mathrm{Cl}: 0.53-0.81)$, cigarette smoking $(\mathrm{RR}=0.67 ; 95 \% \mathrm{Cl}: 0.57-0.79)$, and age $(\mathrm{RR}=0.77 ; 95 \% \mathrm{Cl}$ : 0.71-0.84). The dose-response meta-analysis showed a lower bladder cancer risk $(\mathrm{RR}=0.95$; 95\% Cl: 0.92-0.98) for each live birth increase in parous women. No evidence of publication bias or significant heterogeneity was detected in the above-mentioned analyses.

Conclusions: The finding from current meta-analysis suggest that parity may be related to decreased risk of bladder cancer.

Keywords: Parity, Bladder cancer, Meta-analysis, Women's health

\section{Background}

Bladder cancer $(\mathrm{BC})$ is one of the most common genitourinary malignancies in the United States, with an estimated 76, 960 newly diagnosed cases and 16390 deaths in 2016 [1]. Incidence rate of BC is notably gender-specific with men having a 3 4 fold greater risk than women for developing the disease [1]. Given the evidence from current knowledge, the gender disparity of incidence rate for $\mathrm{BC}$ cannot be completely explained by known risk factors, such as cigarette smoking and occupation [2].

Although the exact biological mechanisms for the gender disparity in $\mathrm{BC}$ development and progression are not well established, some studies have suggested that sex hormones and their receptors may contribute to this

\footnotetext{
* Correspondence: hanpingwch@163.com

${ }^{\dagger}$ Equal contributors

Department of Urology, Institute of Urology, West China Hospital, Sichuan University, Guoxue Xiang\#37, Chengdu, Sichuan 610041, China
}

difference [3-5]. During pregnancy, changes in maternal hormones, as well as physical structure changes in the pelvic or lower abdominal region following childbirth, may lead to etiological changes that decrease $\mathrm{BC}$ risk. Till date, numerous observational studies [6-11] have investigated the roles of reproductive factors, such as age at menarche and menopause, parity, age at first birth, and number of children, in the development of $\mathrm{BC}$, but results have been inconsistent, probably because of limited sample size included each individual study. Although published reviews and meta-analyses have focused on this topic $[12,13]$, up to now, a comprehensive and quantitative assessment of the relationship between parity number and $\mathrm{BC}$ risk has not been reported.

Therefore, we find it necessary to further assess the relationship between parity and $\mathrm{BC}$ risk by conducting a meta-analysis of current epidemiologic studies and providing a quantitative dose-response analysis. 


\section{Methods}

This study protocol was approved by the institutional review board at the West China School of Medicine before initiation and don't need ethical standard statement.

\section{Literature search and eligibility criteria}

We searched online databases MEDLINE and EMBASE for the studies assessing the relationship of parity and BC risk before Sep 2016, using the following terms with every possible combination considered: parity, pregnancy, reproductivity, fertility, bladder, genitourinary tract, cancer, carcinoma, tumor. We searched the references of all eligible publications to identify additional relevant publications. Studies were included if they met the following criteria: (1) the study had a prospective or case-control design; (2) the study evaluated the relationship between parity and $\mathrm{BC}$ risk; (3) data were provided or would allow the calculation of relative risk (RR) or odds ratio (OR) and a 95\% confidence intervals (CI). Exclusion criteria were as follows: (1) was not involved with the associations between parity and BC risk; (2) non-human studies, reviews, and comments; (3) studies not reporting primary outcomes; (4) studies based on overlapping patients. When duplicate publications were identified or data in separate publications originated from the same cohort, we used the publication with the largest number of cases and the most applicable data.

\section{Data extraction and quality assessment}

Data were independently extracted from the included studies by two investigators (YJB and XMW), and disagreement was settled by discussion with the third investigator. The following data were extracted from each study: first author' name, publication year, country of study, participant demographics, sample size, duration of follow-up or study period, parity number categories, corresponding OR/RR (with their 95\% CIs) for each category, and variables adjusted for in the analysis.

The methodological quality assessment was conducted for each of the included studies using the NewcastleOttawa Scale quality assessment [14] on three broad perspectives: selection, comparability and exposure or outcome. Two investigators read each included study and scored them independently. Disagreements were resolved by consensus.

\section{Statistical analysis}

Given that bladder cancer is a rare disease, the OR was assumed to be the same as the RR and we therefore report all effect sizes as RR for simplicity. We calculated summary RRs and 95\% CIs associated with parity and $\mathrm{BC}$ risk, if the study considered nulliparous as a reference. Between-study heterogeneity was evaluated with $Q$ and $\mathrm{I}^{2}$ statistics [15]. For the Q-test, we used $P<0.10$ as evidence of heterogeneity. An $\mathrm{I}^{2}$ score exceeding $50 \%$ is considered to indicate the presence of heterogeneity. The random effect model was used to provide summary estimations if there was heterogeneity, or else the fixed effect model was used. Heterogeneity was explored by stratified analysis. Publication bias was explored using Begg's and Egger's test $[16,17]$ and funnel plots. $P<0.05$ indicated the existence of publication bias.

We carried out a dose-response meta-analysis using the method proposed by Greenland et al. [18] and Orsini et al. [19] to estimate study-specific slopes (linear trends) and 95\% CIs from the log-RRs and CIs across the categories of parity number. This analysis requires the number of cases and controls for case-control studies or the number of cases and person-years for cohort studies, and the RR with 95\% CI for at least three quantitative categories of parity number are presented. The value assigned to each category was the midpoint of the upper and lower boundaries and was adjusted for half range of the neighborhood categories when categories were openended. Random-effects model was applied in our study. This was done by modeling parity number using restricted cubic splines with three knots at percentiles 5, 50 , and $95 \%$ of the distribution. A $P$ value for nonlinearity was computed by testing the null hypothesis that the coefficient of the second spline was equal to zero. Statistical analyses were performed with Stata version 12.0 software (Stata Corp, College Station, TX).

\section{Results}

Study characteristics and quality assessment

The article selection process is shown in Fig. 1. Thirteen articles [6-13, 20-24] met the selection criteria. Two studies reported data on the same cohort $[9,22]$ and we included the more recently one which reported the

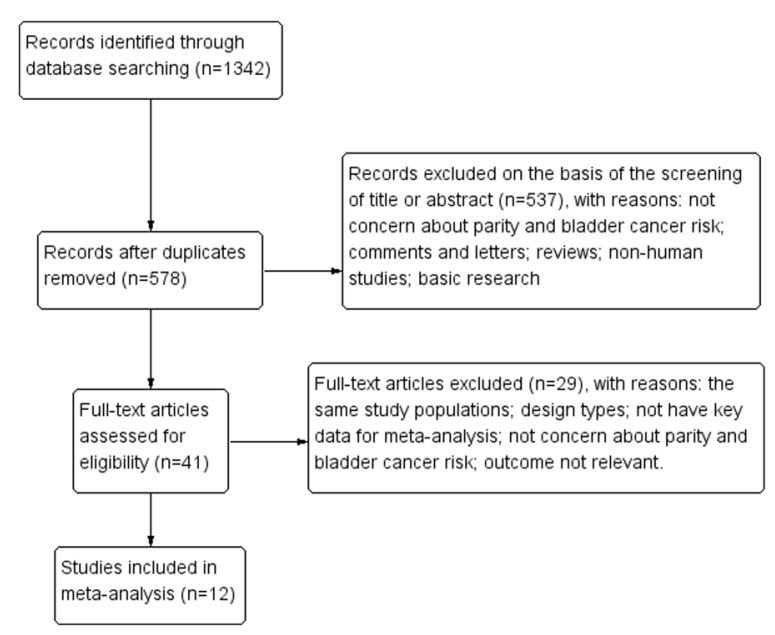

Fig. 1 Flow diagram of the study selection process 
Bai et al. BMC Cancer (2017) 17:31

Page 3 of 9

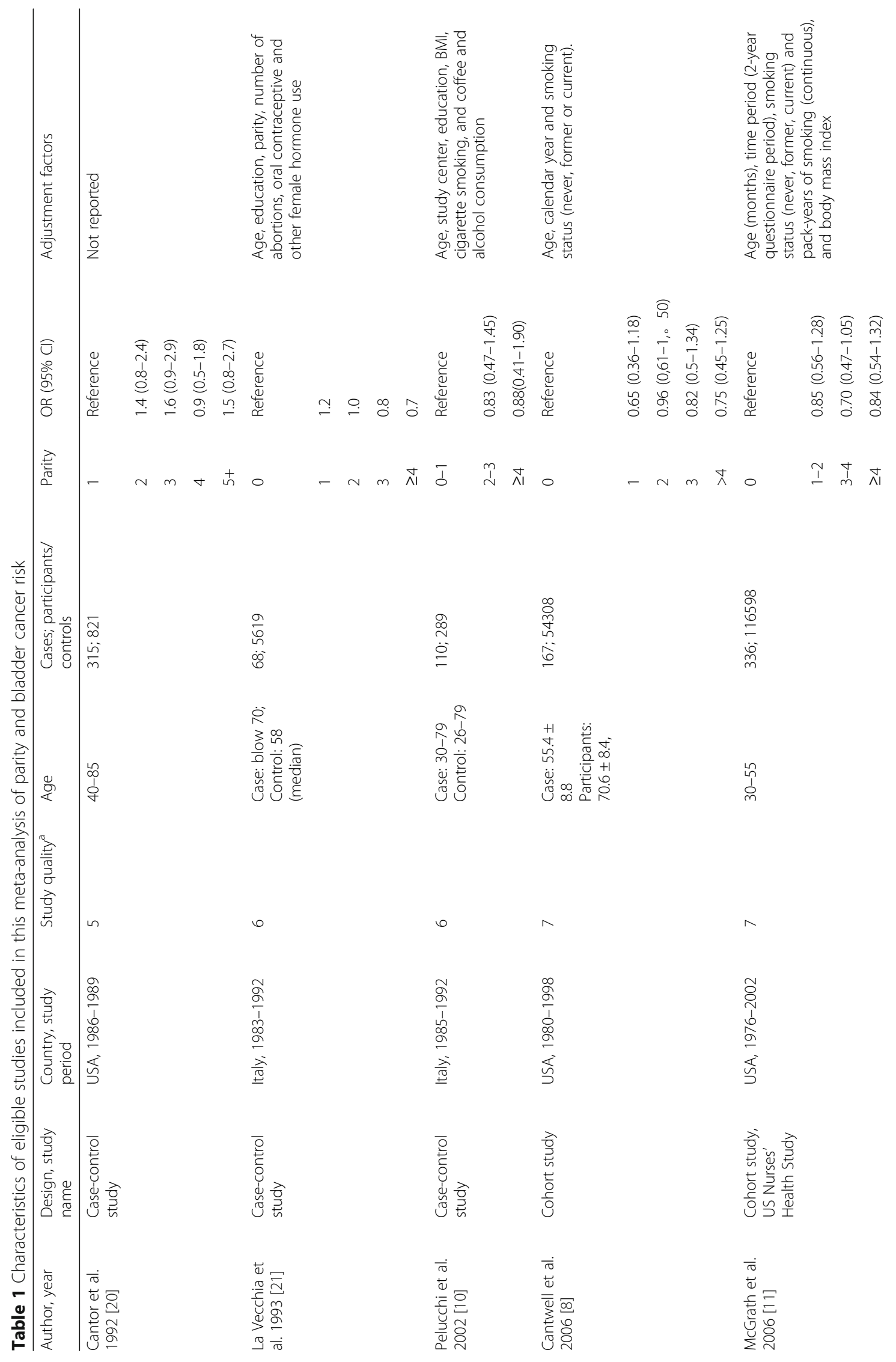




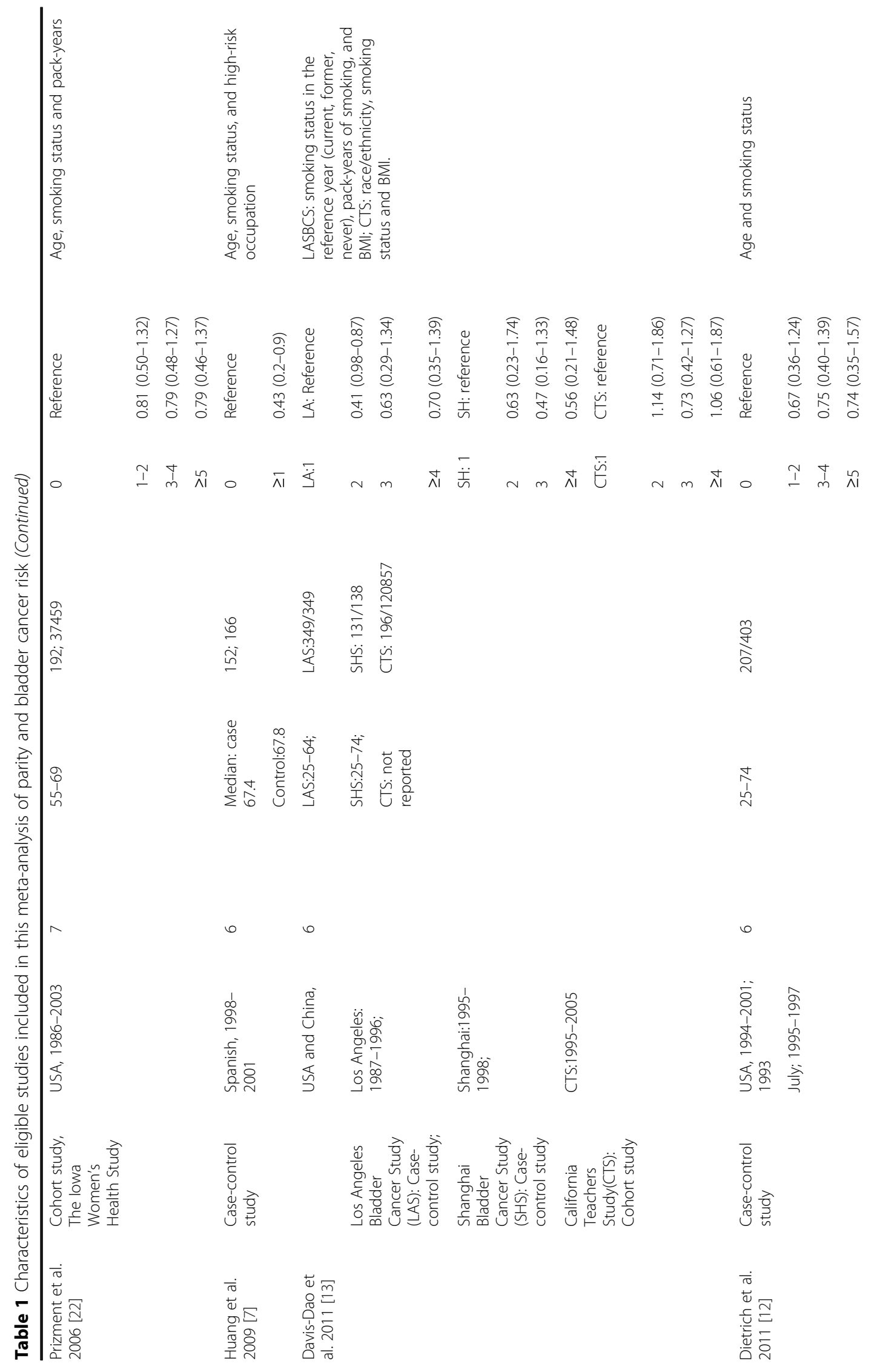




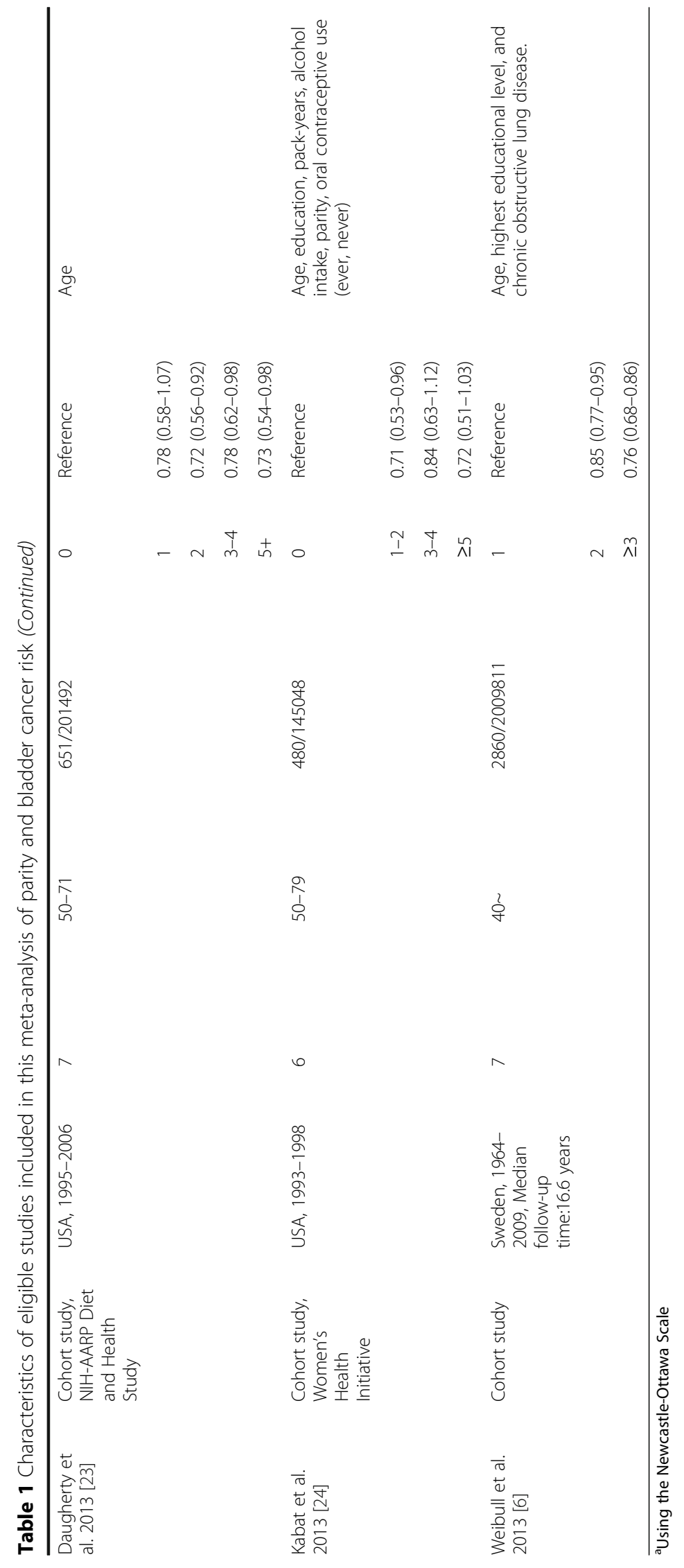


largest number of cases [22]. Thus, 12 publications were included in this meta-analysis $[6-8,10-13,20-24]$, and their characteristics are presented in Table 1 . These studies included a total of 6,214 cases and 2,693,350 non-cases and were published from 1992 to 2013. Among these studies, one study reported three separate outcomes: the Los Angeles Bladder Cancer Study, the Shanghai Bladder Cancer Study, and the California Teachers Study [13]. Thus, the present study used seven outcomes from case-control studies and seven outcomes from cohort studies to produce a metaanalysis. Of the included studies, 13 were conducted in Europe, nine in America and one in China. All studies included met quality criteria ranging from 5 to 7 stars.

\section{Ever versus never parity}

All included studies in present study investigated the association between ever parity and $\mathrm{BC}$ risk. The summary multivariable-adjusted $\mathrm{RR}$ of $\mathrm{BC}$ for ever versus nulliparous was $0.76(95 \% \mathrm{CI}, 0.70-0.82)$, without heterogeneity $\left(\mathrm{I}^{2}=0 \%, p=0.795\right.$, Fig. 2), indicating an inverse association between parity and $\mathrm{BC}$ risk. For women who have never smoked, the summary RR of BC for ever versus nulliparous was 0.47 (95\% CI, 0.35-0.63), without heterogeneity $\left(\mathrm{I}^{2}=0 \%, p=0.562\right)$. For women who have ever smoked, the summary RR was 0.90 (95\% CI, 0.67-1.21) for ever versus nulliparous, without heterogeneity $\left(\mathrm{I}^{2}=0 \%, p=0.531\right)$.

\section{Differences with parity number}

Six cohort and six case-control studies investigated possible association between parity and $\mathrm{BC}$ risk. The results of the effects of different parity number on $\mathrm{BC}$ risk are presented in Table 2. To clarify the effects, we divided the parity number into three groups. The first group (1-2 births) contained seven reports, compared with nulliparous,, the pooled RR of $\mathrm{BC}$ associated with giving birth to two children was 0.82 (95\% CI 0.71-0.94) with $\mathrm{I}^{2}=17.7 \% \quad(P=0.295)$. The second group (3-4 births) contained seven reports, compared with nulliparous, the overall RR of BC was 0.79 (95\% CI 0.68-0.91) with $\mathrm{I}^{2}=0 \%(P=0.997)$. The third group ( $\geq 5$ births $)$ contained six reports, compared with nulliparous, the overall RR of BC was 0.76 (95\% CI 0.66-0.88) with $\mathrm{I}^{2}=0 \%$ $(P=0.994)$.

\section{Dose-response meta-analysis}

Dose-response from nine studies [6, 8, 11-13, 20-23] showed a decreased in BC risk of 0.95 (95\% CI: 0.92-0.98) per live birth increase, without heterogeneity $\left(\mathrm{I}^{2}=12.79 \%\right.$, $P=0.7832$ ). Compared with nulliparous individuals, the pooled RRs $(95 \% \mathrm{CI})$ of $\mathrm{BC}$ were $0.84(0.76-0.94), 0.76$ (0.67-0.87), 0.74 (0.65-0.85), 0.75 (0.66-0.85), and 0.76 $(0.65-0.88)$ for $1,2,3,4$, and 5 live births, respectively (Fig. 3).

\section{Publication bias}

No evidence of a significant publication bias was observed in our analyses as assessed using the Egger's

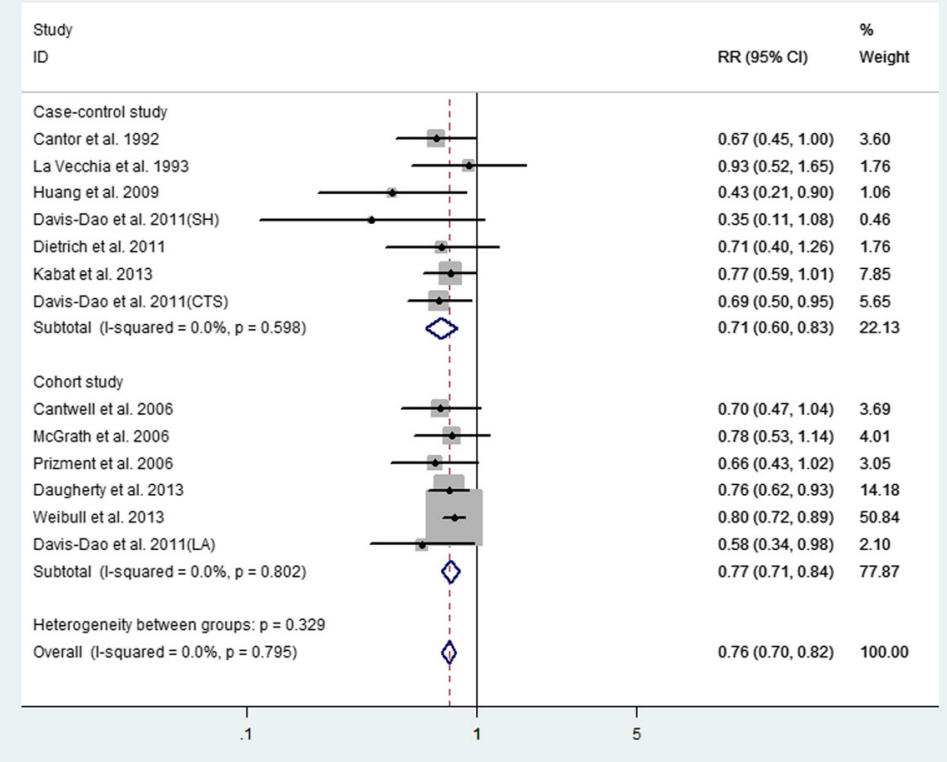

Fig. 2 Forest plot (fixed-effects model) of ever parity and bladder cancer risk 
Table 2 Summary risk estimates of the association between parity and bladder cancer

\begin{tabular}{|c|c|c|c|c|}
\hline & No. of reports & RR $(95 \% \mathrm{Cl})$ & $I^{2}(\%)$ & $P$ value \\
\hline Overall & 13 & $0.76(0.70-0.82)$ & 0 & 0.795 \\
\hline \multicolumn{5}{|l|}{ Number of parity } \\
\hline $1 \sim 2$ vs. 0 & 7 & $0.82(0.71-0.94)$ & 17.7 & 0.295 \\
\hline $3 \sim 4$ vs. 0 & 7 & $0.79(0.68-0.91)$ & 0 & 0.997 \\
\hline$\geq 5$ vs. 0 & 6 & $0.76(0.66-0.88)$ & 0 & 0.994 \\
\hline \multicolumn{5}{|l|}{ Subgroup analysis } \\
\hline \multicolumn{5}{|l|}{ Study design } \\
\hline Cohort study & 6 & $0.77(0.71-0.84)$ & 0 & 0.802 \\
\hline Case-control study & 7 & $0.71(0.60-0.83)$ & 0 & 0.598 \\
\hline \multicolumn{5}{|l|}{ Number of cases } \\
\hline$<250$ & 7 & $0.68(0.56-0.81)$ & 0 & 0.673 \\
\hline$>250$ & 6 & $0.78(0.71-0.84)$ & 0 & 0.841 \\
\hline \multicolumn{5}{|l|}{ Location } \\
\hline USA & 9 & $0.72(0.65-0.81)$ & 0 & 0.989 \\
\hline Others & 4 & $0.79(0.71-0.87)$ & 39.7 & 0.174 \\
\hline \multicolumn{5}{|l|}{ Smoking } \\
\hline Never smoking & 5 & $0.47(0.35-0.63)$ & 0 & 0.562 \\
\hline Ever smoking & 4 & $0.90(0.67-1.21)$ & 0 & 0.531 \\
\hline \multicolumn{5}{|c|}{ Adjustment for smoking } \\
\hline Yes & 8 & $0.67(0.57-0.79)$ & 0 & 0.815 \\
\hline No & 5 & $0.79(0.72-0.86)$ & 0 & 0.882 \\
\hline \multicolumn{5}{|l|}{ Adjustment for age } \\
\hline Yes & 9 & $0.77(0.71-0.84)$ & 0 & 0.850 \\
\hline No & 4 & $0.65(0.52-0.81)$ & 0 & 0.684 \\
\hline \multicolumn{5}{|l|}{ Adjustment for BMI } \\
\hline Yes & 5 & $0.66(0.53-0.81)$ & 0 & 0.469 \\
\hline No & 8 & $0.76(0.70-0.82)$ & 0 & 0.952 \\
\hline
\end{tabular}

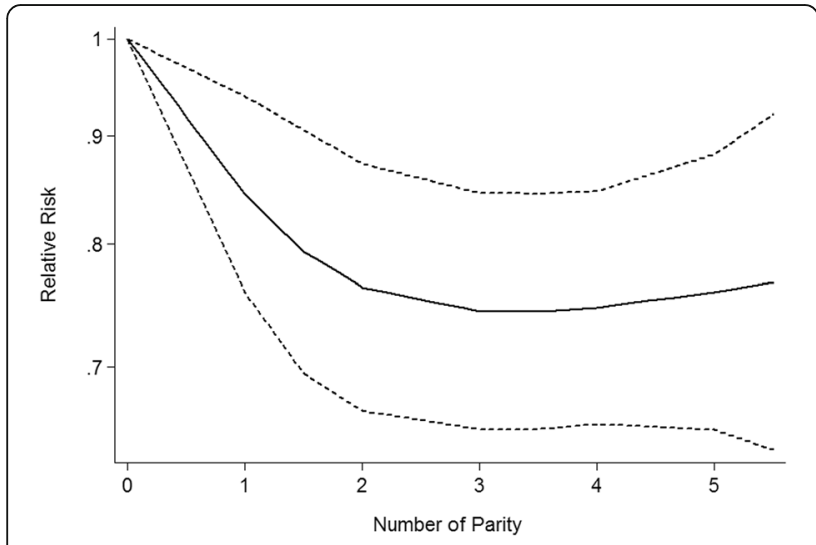

Fig. 3 Nonlinear dose-response relationship between parity and bladder cancer risk test or Begg's test and no asymmetry was seen in the funnel plots of included studies.

\section{Subgroup analyses}

To avoid the influence of cigarette smoking, we evaluated the influence of smoking status by adjustment in the eight reports that considered smoking. However, when data were stratified by adjustment for smoking, we did not find a significant difference between summary RRs that were adjusted and those that were not adjusted for smoking (Table 2). Moreover, significant inverse associations were persisted after the subgroup analyses stratified by whether the study included adjustment for specific potential confounders, such as age, Body Mass Index (BMI), type of control subjects or others potential confounders (Table 2). An additional file shows this in more detail (see Additional file 1).

\section{Discussion}

Numerous epidemiological studies have focused on BC risk factors in order to explain the gender disparity in $\mathrm{BC}$ incidence, while there is also a great interest in identifying factors that affect the risk of $\mathrm{BC}$ among women. Although previous studies have reported on the associations between parity and BC, to the best of our knowledge, no other earlier studies have clearly documented a dose-response pattern between parity number and $\mathrm{BC}$ risk. In present study, we conducted a dose-response meta-analysis to characterize the association between parity and BC risk. Findings from the present study indicated that parous was significantly inversely associated with $\mathrm{BC}$ risk compared with nulliparous, especially for non-smokers. Overall, the risk of BC decreased by $24 \%$ for women who had given birth and 53\% for those who had never smoked and were ever parous.

Although the exact mechanisms underlying this inverse association between parity and $\mathrm{BC}$ risk are not completely established, several potential mechanisms have been proposed. First, during pregnancy, estrogen and progesterone levels increase drastically and induce substantial alterations to the structure, function, and histology of the bladder [25], possibly affecting the development and progression of $\mathrm{BC}$. Both estrogen and progesterone receptors are found in bladder tissues suggesting that endocrine regulation could directly influence BC development [26]. Shen et al. [27] found that antiestrogens have an inhibitory effect on the growth of $\mathrm{BC}$ cells in vitro, indicating that estrogens may increase the development and growth of bladder malignancies. Some research has reported that progesterone suppresses the activity of the estrogen receptor during pregnancy [28]. Therefore, estrogen and progesterone have an antagonistic effects on human cells. The substantial increased in their levels during pregnancy may responsible for the decreased risk of $\mathrm{BC}$ for women. 
Moreover, a hormone-related protective effect based on the prity number may mirror the lifetime period of lactation and prolonged oxytocin inhibition of steroid hormones [6].

Second, smoking habits may have influenced the incidence of $\mathrm{BC}$ in women with parity. It is well known that prenatal cigarette smoking exposure may cause detrimental effects on reproductive health [29]. Therefore, most smokers who prepare for pregnancy are more likely to quit smoking. Thus, compared with nulliparous female smokers, parous smokers who quit smoking may have a shorter smoking exposure history and reduction of pack years, and this may affect their BC risk. In addition, cumulative effect of abandon smoking following multiple pregnancies may also associate to decrease the subsequent risk of BC. The findings of our study suggest that the negative correlation between parity and $\mathrm{BC}$ appears more remarkable among women who were never exposed to cigarettes, with these parous women experiencing at least a $53 \%$ decreased risk of $\mathrm{BC}$ compared with nulliparous women. However, such a dramatic risk reduction was not apparent among smokers. The reasons for this results of subgroup analysis may be that the effect of smoking on $\mathrm{BC}$ is so huge that for the development of the disease minor influence factors such as parity are less relevant. In case of never smokers, these minor influence factors play indeed a role.

Third, structural changes in the pelvic organs and pelvic floor organization following pregnancy may induce a decreased risk for $\mathrm{BC}$ in parous women. Childbirth is an established risk factor for lower urinary tract dysfunction, such as increased urinary frequency, stress incontinence, and overactive bladder [30], but the possible relationship with $\mathrm{BC}$ remains unclear. It is well known that $\mathrm{BC}$ risk is related to the contact time of the urothelium with carcinogens in urine. Some study reported that increased water intake and urination frequency may lessen contact time of urinary carcinogens with urothelium of the bladder, thus, diminish the bladder cancer risk [31, 32]. Zhang et al. [31] found that increasing urination frequency during daytime was associated with decreased risk of bladder cancer. Silverman et al. [32] suggested that nocturia may be a powerful factor in reducing $\mathrm{BC}$ risk. Based on the results of above studies, we can be reasonable to assume that lower urinary tract dysfunction after childbirth has a protective effect on $\mathrm{BC}$ risk, and this may be associated with shorter duration of exposure to urine carcinogens in the bladder. Further research should verify this hypothesis.

Meta-analyses of observational studies are prone to confounding, selection, and information bias as the included observational studies and can present particular challenges that may distort the results. However, our study has some strengths. First, we searched 2 electronic databases, which ensured a broad scope, and we included seven cohorts and seven case-control studies that involved a total of 6,214 cases and $2,693,350$ non-cases. This large sample size should have provided sufficient statistical power to detect this potential relationship. Second, to control misclassification, we conducted a dose-response meta-analysis. This is the most comprehensive meta-analysis evaluating the associations between parity and $\mathrm{BC}$. Third, no publication biases were detected in present study and outcome may be unlikely to remain unreported as studies with complex assessment of exposure.

\section{Conclusions}

This current dose-response meta-analysis indicates that women with parity have an inversely associated $\mathrm{BC}$ risk compared with nulliparous women. The exact mechanism underlying this protective effect requires further investigation.

\section{Additional file}

Additional file 1: Subgroup analyses of forest plots included in our meta-analysis. (ZIP $143 \mathrm{~kb}$ )

\section{Abbreviations \\ BC: Bladder cancer; BMI: Body mass index; Cl: Confidence interval; OR: Odds ratio; RR: Relative risk \\ Acknowledgements \\ Thanks to the help of the members of the urology department in West China Hospital of Sichuan University, especially QW, CXP and JHL. \\ Funding \\ This work was collectively supported by grant (National Natural Science Foundation of China (No. 81270841)), and Science \& Technology Pillar Program from Science \& Technology Department of Sichuan Province (2013SZ0034). The funders had no role in study design, data collection and analysis, decision to publish, or preparation of the manuscript.}

Availability of data and materials

All data generated or analysed during this study are included in this published article.

\section{Authors' contributions \\ Conceived and designed the experiments: PH. Analyzed the data: JYB and XMW. Contributed reagents/materials/analysis YBY, YT and JW. Wrote the manuscript: JYB, XMW and JW. All authors have read and approved the final manuscript.}

\section{Competing interests}

The authors declare that they have no competing interests.

Consent for publication

Not applicable.

Ethics approval and consent to participate

Not applicable.

Received: 16 January 2016 Accepted: 20 December 2016

Published online: 06 January 2017 


\section{References}

1. Siegel RL, Miller KD, Jemal A. Cancer statistics, 2016. CA Cancer J Clin. 2016;66:7-30.

2. Hartge P, Harvey EB, Linehan WM, Silverman DT, Sullivan JW, Hoover RN, Fraumeni Jr JF. Unexplained excess risk of bladder cancer in men. J Natl Cancer Inst. 1990:82:1636-40.

3. Bolenz C, Lotan Y, Ashfaq R, Shariat SF. Estrogen and progesterone hormonal receptor expression in urothelial carcinoma of the bladder. Eur Urol. 2009;56:1093-5.

4. Lucca I, Fajkovic H, Klatte T. Sex steroids and gender differences in nonmuscle invasive bladder cancer. Curr Opin Urol. 2014;24:500-5.

5. Gakis G, Stenzl A. Gender-specific differences in muscle-invasive bladder cancer: the concept of sex steroid sensitivity. World J Urol. 2013;31:1059-64.

6. Weibull CE, Eloranta S, Altman D, Johansson AL, Lambe M. Childbearing and the risk of bladder cancer: a nationwide population-based cohort study. Eur Urol. 2013;63:733-8.

7. Huang AT, Kogevinas M, Silverman DT, Malats N, Rothman N, Tardón A, Serra C, García-Closas R, Carrato A, Cantor KP. Bladder cancer and reproductive factors among women in Spain. Cancer Causes Control. 2009;20:1907-13.

8. Cantwell MM, Lacey Jr JV, Schairer C, Schatzkin A, Michaud DS. Reproductive factors, exogenous hormone use and bladder cancer risk in a prospective study. Int J Cancer. 2006;119:2398-401.

9. Tripathi A, Folsom AR, Anderson KE, lowa Women's Health Study. Risk factors for urinary bladder carcinoma in postmenopausal women. The lowa Women's Health Study. Cancer. 2002;95:2316-23.

10. Pelucchi C, La Vecchia C, Negri E, Dal Maso L, Franceschi S. Smoking and other risk factors for bladder cancer in women. Prev Med. 2002;35:114-20.

11. McGrath M, Michaud DS, De Vivo I. Hormonal and reproductive factors and the risk of bladder cancer in women. Am J Epidemiol. 2006;163:236-44.

12. Dietrich K, Demidenko E, Schned A, Zens MS, Heaney J, Karagas MR. Parity, early menopause and the incidence of bladder cancer in women: a case-control study and meta-analysis. Eur J Cancer. 2011;47:592-9.

13. Davis-Dao CA, Henderson KD, Sullivan-Halley J, Ma H, West D, Xiang YB, Gago-Dominguez M, Stern MC, Castelao JE, Conti DV, Pike MC, Bernstein L, Cortessis VK. Lower risk in parous women suggests that hormonal factors are important in bladder cancer etiology. Cancer Epidemiol Biomarkers Prev. 2011;20:1156-70

14. Stang A. Critical evaluation of the Newcastle-Ottawa scale for the assessment of the quality of nonrandomized studies in meta-analyses. Eur J Epidemiol. 2010;25:603-5.

15. Higgins JP, Thompson SG, Deeks JJ, Altman DG. Measuring inconsistency in meta-analyses. BMJ. 2003;327:557-60.

16. Begg CB, Mazumdar M. Operating characteristics of a rank correlation test for publication bias. Biometrics. 1994;50:1088-101.

17. Egger M, Davey SG, Schneider M, Minder C. Bias in meta-analysis detected by a simple, graphical test. BMJ. 1997;315:629-34.

18. Greenland S, Longnecker MP. Methods for trend estimation from summarized dose-response data, with applications to meta-analysis. Am J Epidemiol. 1992;135:1301-9.

19. Orsini N, Bellocco R, Greenland S. Meta-analysis for linear and nonlinear dose-response relations: examples, an evaluation of approximations, and software. Am J Epidemiol. 2012;175:66-73.

20. Cantor KP, Lynch CF, Johnson D. Bladder cancer, parity, and age at first birth. Cancer Causes Control. 1992;3:57-62.

21. La Vecchia C, Negri E, Franceschi S, Parazzini F. Long-term impact of reproductive factors on cancer risk. Int J Cancer. 1993:53:215-9.

22. Prizment $A E$, Anderson KE, Harlow BL, Folsom AR. Reproductive risk factors for incident bladder cancer: lowa Women's Health Study. Int J Cancer. 2006;120:1093-8.

23. Daugherty SE, Lacey Jr JV, Pfeiffer RM, Park Y, Hoover RN, Silverman DT. Reproductive factors and menopausal hormone therapy and bladder cancer risk in the NIH-AARP Diet and Health Study. Int J Cancer. 2013;133:462-72.

24. Kabat GC, Kim MY, Luo J, Hou L, Cetnar J, Wactawski-Wende J, Rohan TE. Menstrual and reproductive factors and exogenous hormone use and risk of transitional cell bladder cancer in postmenopausal women. Eur J Cancer Prev. 2013;22:409-16.

25. Rodrìuez LV, Wang B, Shortliffe LM. Structural changes in the bladder walls of pregnant and hormone-treated rats: correlation with bladder dynamics. BJU Int. 2004:94:1366-72
26. Blakeman PJ, Hilton P, Bulmer JN. Cellular proliferation in the female lower urinary tract with reference to oestrogen status. BJOG. 2001;108:813-6.

27. Shen SS, Smith CL, Hsieh JT, Yu J, Kim IY, Jian W, Sonpavde G, Ayala GE, Younes M, Lerner SP. Expression of estrogen receptors-alpha and -beta in bladder cancer cell lines and human bladder tumor tissue. Cancer. 2006;106:2610-6.

28. Batra SC, losif CS. Progesterone receptors in the female lower urinary tract. J Urol. 1987;138:1301-4.

29. Håkonsen LB, Ernst A, Ramlau-Hansen CH. Maternal cigarette smoking during pregnancy and reproductive health in children: a review of epidemiological studies. Asian J Androl. 2014;16:39-49.

30. Chaliha C, Stanton SL. Urological problems in pregnancy. BJU Int. 2002:89:469-76

31. Zhang W, Xiang YB, Fang RR, Cheng JR, Yuan JM, Gao YT. Total fluid intake, urination frequency and risk of bladder cancer: a population-based casecontrol study in urban Shanghai. Zhonghua Liu Xing Bing Xue Za Zhi. 2010;31:1120-4.

32. Silverman DT, Alguacil J, Rothman N, Real FX, Garcia-Closas M, Cantor KP, Malats N, Tardon A, Serra C, Garcia-Closas R, Carrato A, Lloreta J, Samanic C, Dosemeci M, Kogevinas M. Does increased urination frequency protect against bladder cancer? Int J Cancer. 2008;123:1644-8.

\section{Submit your next manuscript to BioMed Central and we will help you at every step:}

- We accept pre-submission inquiries

- Our selector tool helps you to find the most relevant journal

- We provide round the clock customer support

- Convenient online submission

- Thorough peer review

- Inclusion in PubMed and all major indexing services

- Maximum visibility for your research

Submit your manuscript at www.biomedcentral.com/submit
) Biomed Central 